\title{
An Improved Sensorless DTC Scheme for EV Induction Motors
}

\author{
F. Khoucha, K. Marouani, A. Haddoun, A. Kheloui and M.E.H. Benbouzid, Senior Member, IEEE
}

\begin{abstract}
In this paper a sensorless control is proposed to increase the efficiency of a Direct Torque Control (DTC) of an induction motor propelling an Electric Vehicle (EV). The proposed scheme uses an adaptive flux and speed observer that is based on a full order model of the induction motor. Moreover, it is evaluated on an EV global model taking into account the vehicle dynamics. Simulations have been firstly carried out on a test vehicle propelled by a $37-\mathrm{kW}$ induction motor to evaluate the consistency and the performance of the proposed control approach. The commonly used European drive cycle ECE-15 is adopted for simulation. The obtained results seem to be very promising. Then, the proposed control approach has been experimentally implemented, on a TMS320F240 DSP-based development board, and tested on $1-\mathrm{kW}$ induction motor. Experimental results show that the proposed control scheme is effective in terms of speed and torque performances. Indeed, it allows speed and torque ripple minimization. Moreover, the obtained results show that the proposed sensorless DTC scheme for induction motors is a good candidate for EVs propulsion.
\end{abstract}

Index Terms-Electric vehicle, Induction motor, sensorless drive, direct torque control, vehicle dynamics.

\section{INTRODUCTION}

Recently a lot of effort was focused towards development of high performance EV drives. This is mainly to reduce the environmental pollution due to emissions from the internal combustion engine (ICE) driven vehicles. EVs are already commercially available; however, they have not yet used the most remarkable advantages of electric motors. Indeed, an electric motor offers very fast response and can be controlled in a much better way; therefore, motion control through precise control of the motors has definite advantage over the ICE driven vehicles. Moreover, adhesion characteristics between tire and road surface are greatly affected by the traction motor control. This means that EVs stability and safety can be addressed and then improved by means of motor control.

The electric propulsion system is the heart of EV [1]. It consists of the motor drive, transmission device, and wheels.

F. Khoucha*, A. Haddoun ${ }^{* *}$ and M.E.H. Benbouzid are with the Laboratoire d'Ingénierie Mécanique et Electrique (LIME), University of Western Brittany, Rue de Kergoat - BP 93169, 29231 Brest Cedex 3, France (phone: +33 $29801 \quad 80$ 07; fax: +33 $29801 \quad 66$ 43; e-mail: m.benbouzid@ieee.org). "F. Khoucha is also with the Electrical Engineering Department, Polytechnic Military Academy, 16111 Algiers, Algeria. ${ }^{* *} \mathrm{~A}$. Haddoun is also with the University of Oum El Bouaghi, 04000 Oum El Bouaghi, Algeria.

K. Marouani and A. Kheloui are with the Electrical Engineering Department, Polytechnic Military Academy, 16111 Algiers, Algeria.
In fact, the motor drive, composed by the electric motor, the power converter, and the electronic controller, is the core of the EV propulsion system. The motor drive is configured to respond to a torque demand set by the driver. The accelerator position provides a torque demand as fraction of the maximum available torque. Similarly, the first portion of the brake pedal travel is used to derive a regenerative torque demand; the remaining pedal travel brings in a set of standard mechanical brakes.

For EVs propulsion, the cage induction motor seems to be candidate that better fulfils the propulsion major features [2$3]$. Induction motor drives control techniques are well treated in the literature. The most popular is the so-called vector control technique that is now used for high impact automotive applications (EV and $\mathrm{HEV}$ ). In this case, the torque control is extended to transient states and allows better dynamic performances [4]. Among these techniques, DTC appears to be very convenient for EV applications [5-7].

The implementation of direct torque control technique requires precise knowledge of the rotor or stator flux level and position. If a mechanical speed sensor is mounted on the motor shaft, different ways can be used to obtain the flux estimate. But, the current tendency is to eliminate mechanical transducers. Indeed, they are noise sensitive, expensive, bulky, and they tend to reduce the global drive reliability especially in hostile environments that is case of the induction motor within an EV. In this context, several methods have been proposed this last decade for induction motors speed sensorless control [8-10]. Adaptive speed observers seem to be among the most promising methods thanks to their good performance versus computing time ratio. They have the advantage of providing both flux and mechanical speed estimates without problems of open-loop integration. Besides, the adaptive observer has the interesting property to provide a mechanism for on-line tuning of key model parameters such as the stator or rotor resistance and then to compensate for their drift due to motor heating for example [11].

In this paper a sensorless control is proposed to increase the efficiency of a direct torque Direct Torque Control (DTC) of an induction motor propelling an Electric Vehicle (EV). The proposed scheme uses an adaptive flux and speed observer that is based on a full order model of the induction motor. The objective is to test the effectiveness of the proposed strategy on the whole vehicle and not on the sole induction motor. Simulations have been firstly carried out on a test vehicle propelled by a $37-\mathrm{kW}$ induction motor to evaluate the consistency and the performance of the proposed control approach. Then, the proposed control approach has been experimentally implemented, on a TMS320F240 DSP-based development board, and tested on 1-kW induction motor. 


\section{VEHICLE DYNAMIC ANALYSIS}

\section{A. Nomenclature}

$v=$ vehicle speed;

$\alpha=$ Grade angle;

$P_{v}=$ Vehicle driving power;

$F_{w}=$ Road load;

$F_{r o}=$ Rolling resistance force;

$F_{s f}=$ Stokes or viscous friction force;

$F_{a d}=$ Aerodynamic drag force;

$F_{c r}=$ Climbing and downgrade resistance force;

$\mu=$ Tire rolling resistance coefficient $(0.015<\mu<0.3)$;

$m=$ Vehicle mass;

$g=$ Gravitational acceleration constant;

$k_{A}=$ Stokes coefficient;

$\xi=$ Air density;

$C_{w}=$ Aerodynamic drag coefficient $\left(0.2<C_{w}<0.4\right)$;

$A_{f}=$ Vehicle frontal area;

$v_{0}=$ is the head-wind velocity;

$F=$ Tractive force;

$k_{m}=$ Rotational inertia coefficient $\left(1.08<k_{m}<1.1\right)$;

$a=$ Vehicle acceleration;

$J=$ Total inertia (rotor and load);

$\omega_{m}=$ Motor mechanical speed;

$T_{B}=$ Load torque accounting for friction and windage;

$T_{L}=$ Load torque;

$T_{m}=$ Motor torque;

$i=$ Transmission ratio;

$\eta_{t}=$ Transmission efficiency;

$R=$ Wheel radius;

$J_{V}=$ Shaft inertia moment;

$J_{W}=$ Wheel inertia moment;

$\lambda=$ Wheel slip.

\section{B. Dynamics Analysis}

Based on principles of vehicle mechanics and aerodynamics, one can assess both the driving power and energy necessary to ensure vehicle operation (Fig. 1) [5], [12].

1) Road load and tractive force. The road load consists of

$$
F_{w}=F_{r o}+F_{s f}+F_{a d}+F_{c r}
$$

The rolling resistance force $F_{r o}$ is produced by the tire flattening at the roadway contact surface.

$$
F_{r o}=\mu m g \cos \alpha
$$

$\mu$ is nonlinearly dependent of the vehicle speed, tire pressure and type, and road surface characteristic.

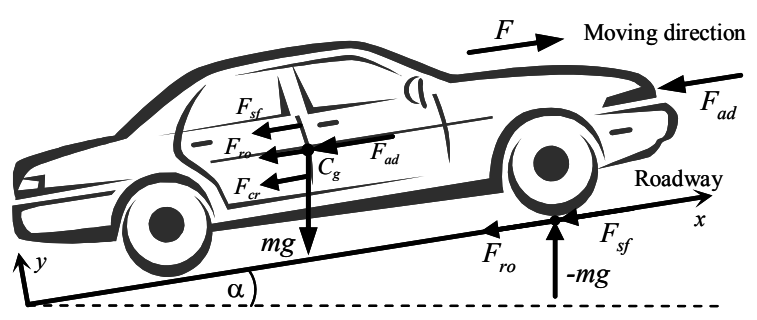

Fig. 1. Elementary forces acting on a vehicle.
It increases with vehicle speed and also during vehicle turning maneuvers. The rolling resistance force can be minimized by keeping the tires as much inflated as possible.

$$
F_{s f}=k_{A} v
$$

Aerodynamic drag, $F_{a d}$, is the viscous resistance of air acting upon the vehicle.

$$
F_{a d}=\frac{1}{2} \xi C_{w} A_{f}\left(v+v_{0}\right)^{2}
$$

The climbing resistance $\left(F_{c r}\right.$ with positive operational sign) and the downgrade force $\left(F_{c r}\right.$ with negative operational sign) is given by

$$
F_{c r}= \pm m g \sin \alpha
$$

The tractive force in an electric vehicle is supplied by the electric motor in overcoming the road load. The equation of motion is given by

$$
k_{m} m \frac{d v}{d t}=F-F_{w}
$$

The net force $\left(F-F_{w}\right)$, accelerates the vehicle (or decelerates when $F_{w}$ exceeds $F$ ).

2) Motor ratings and transmission. The power required to drive a vehicle has to compensate the road load $F_{w}$.

$$
P_{v}=v F_{w}
$$

The mechanical equation (in the motor referential) used to describe each wheel drive is expressed by

$J \frac{d \omega_{m}}{d t}+T_{B}+T_{L}=T_{m}$

The following equation is derived due to the use of a reduction gear.

$$
\left\{\begin{array}{l}
\omega_{\text {Wheel }}=\frac{\omega_{m}}{i} \\
T_{\text {Wheel }}=T_{m} i \eta_{t}
\end{array}\right.
$$

The load torque in the motor referential is given by.

$T_{L}=\frac{T_{L \text { Wheel }}}{i}=\frac{R}{i} F_{\omega}$

The vehicle global inertia moment in the motor referential is given by

$$
\left\{\begin{array}{l}
J=J_{W}+J_{V} \\
J_{V}=\frac{1}{2} m \frac{R^{2}}{i^{2}}(1-\lambda)
\end{array}\right.
$$

If the adhesion coefficient of the road surface is high, then $\lambda$ is usually low and can be neglected.

\section{ADAPTIVE FLUX OBSERVER}

\section{A. Nomenclature}

$i_{s} \quad=$ Stator current; 


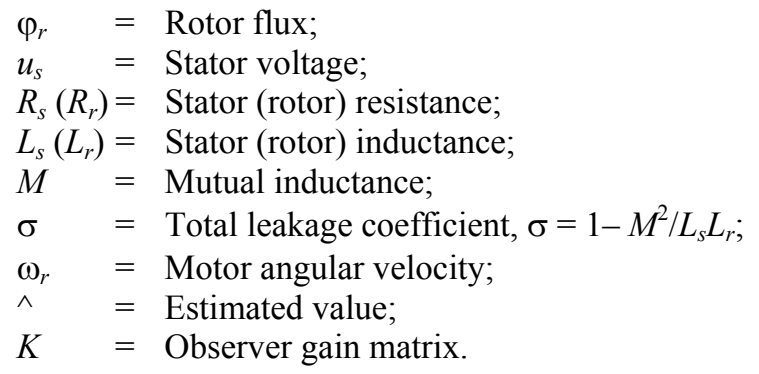

\section{B. Induction Motor Flux Observer}

An induction motor can be described, in the $\alpha-\beta$ stationary reference frame fixed on stator, by the following state equations.

$\left\{\begin{array}{l}\frac{d}{d t}\left[\begin{array}{l}i_{s} \\ \varphi_{r}\end{array}\right]=\left[\begin{array}{ll}A_{11} & A_{12} \\ A_{21} & A_{22}\end{array}\right]\left[\begin{array}{c}i_{s} \\ \varphi_{r}\end{array}\right]+\left[\begin{array}{c}B_{1} \\ 0\end{array}\right] u_{s}=A x+B u \\ i_{s}=C x\end{array}\right.$

Where $i_{s}=\left[\begin{array}{ll}i_{s \alpha} & i_{s \beta}\end{array}\right]^{T}, \varphi_{r}=\left[\begin{array}{ll}\varphi_{r \alpha} & \varphi_{r \beta}\end{array}\right]^{T}, u_{s}=\left[\begin{array}{ll}u_{s \alpha} & u_{s \beta}\end{array}\right]^{T}$

and $\quad A_{11}=-\left(\frac{1-\sigma}{T_{r}}+\frac{1}{T_{s}}\right) / \sigma I, A_{12}=M / \sigma L_{r} L_{s} T_{r} I-\omega_{r} J$

$$
\begin{aligned}
& A_{21}=1 / \sigma L_{r} I, A_{22}=-I / T_{r}+\omega_{r} J, B_{1}=1 / \sigma L_{r} I \\
& C=\left[\begin{array}{ll}
I & 0
\end{array}\right], I=\left[\begin{array}{ll}
1 & 0 \\
0 & 1
\end{array}\right], J=\left[\begin{array}{cc}
0 & -1 \\
1 & 0
\end{array}\right]
\end{aligned}
$$

Therefore, a state observer that provides rotor flux estimates is given by

$$
\frac{d}{d t} \hat{x}=\hat{A} \hat{x}+B u+K\left(\hat{i}_{s}-i_{s}\right)
$$

\section{B. Adaptive Flux Observer for Speed Estimation}

The induction motor speed in the above observer is not measured and is treated as an unknown parameter. By adding an adaptive scheme for estimating the rotor speed, both states and unknown parameters can be estimated simultaneously. Using Lyapunov stability theory, we can build a mechanism to adapt the mechanical speed from the asymptotic convergence condition of the state variables estimation errors.
$\hat{\omega}_{r}=K_{I \omega} \int\left[\hat{\varphi}_{r \beta} e_{i s \alpha}-\hat{\varphi}_{r \alpha} e_{i s \beta}\right] d t$

Although the adaptive scheme is derived under a motor constant speed consideration, in practice it can change quickly. In order to improve the speed estimation algorithm dynamic behavior, a proportional term can be added [13]. The estimated speed becomes

$$
\hat{\omega}_{r}=K_{I \omega} \int\left[\hat{\varphi}_{r \beta} e_{i s \alpha}-\hat{\varphi}_{r \alpha} e_{i s \beta}\right] d t+K_{P \omega}\left[\hat{\varphi}_{r \beta} e_{i s \alpha}-\hat{\varphi}_{r \alpha} e_{i s \beta}\right]
$$

\section{DiRECT TORQUE CONTROL}

A block diagram of the Direct Torque Control scheme is shown by Fig. 2. The control system comprises three basic functions: a two-level hysteresis controller for flux control, a three-level hysteresis controller for torque control, and an optimal switching vector look-up table, The observer estimates the developed torque, stator flux, and shaft speed using measurements of two stator phase currents and the dclink voltage $\left(V_{d c}\right)$. Torque and flux references are compared to their estimated values and control signals are generated using a torque and flux hysteresis control method. The switching vector look-up table (Fig. 3) gives the optimum selection of the switching vectors for all the possible stator flux-linkage space-vector positions. Speed control is achieved using a PI speed controller.

The voltage sensor measures the dc-link voltage that, in conjunction with the knowledge of the switching status of the six controlled power switches of the inverter, is used to compute the stator voltages of the motor using the inverter voltage vector.

$\left\{\begin{array}{l}V_{s \alpha}=\frac{2}{3} V_{d c}\left(S_{a}-\frac{S_{b}+S_{c}}{2}\right) \\ V_{s \beta}=\frac{1}{\sqrt{3}} V_{d c}\left(S_{b}-S_{c}\right)\end{array}\right.$

The $\alpha-\beta$ stator current space vector components are calculated as follows

$\left\{\begin{array}{l}i_{s \alpha}=i_{S a} \\ i_{s \beta}=\frac{i_{S a}+2 i_{S b}}{\sqrt{3}}\end{array}\right.$

The stator flux is a function of the rotor flux that is given by the adaptive flux observer and is calculated by

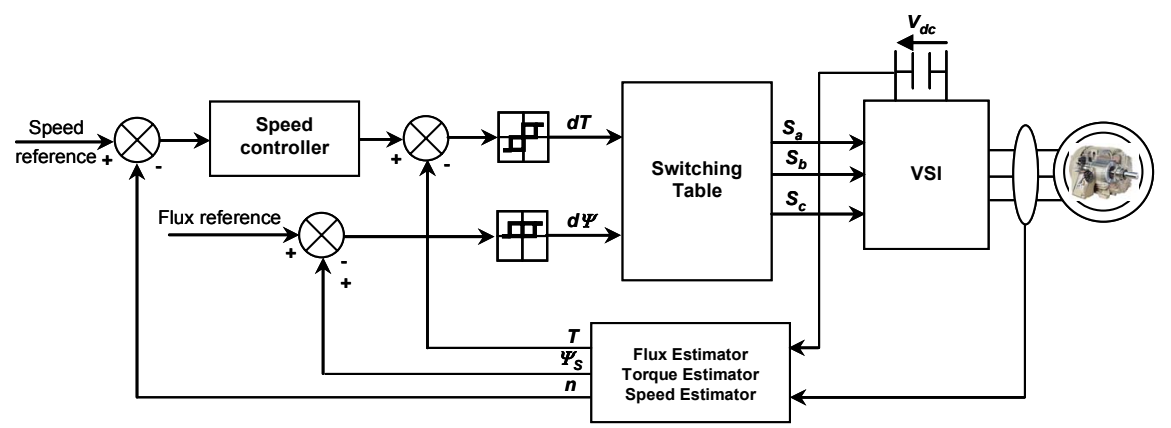

Fig. 2. Typical structure of a sensorless DTC induction motor. 


$$
\left\{\begin{array}{l}
\varphi_{s \alpha}=\sigma L_{s} i_{s \alpha}+\frac{M}{L_{r}} \varphi_{r \alpha} \\
\varphi_{s \beta}=\sigma L_{s} i_{s \beta}+\frac{M}{L_{r}} \varphi_{r \beta}
\end{array}\right.
$$

Then the stator flux and the electromagnetic torque are calculated as

$\left|\varphi_{s}\right|=\sqrt{\varphi_{s \alpha}^{2}+\varphi_{s \beta}^{2}}$

$T_{e}=\frac{3}{2} p\left(\varphi_{s \alpha} i_{s \beta}-\varphi_{s \beta} i_{s \alpha}\right)$

where $p$ is the pole pair number.

As shown in Fig. 3, a switching table is used for the inverter control such that the torque and flux errors are kept within the specified bands. The torque and flux errors are respectively defined by

$$
\left\{\begin{array}{l}
\Delta T_{e}=T_{e}-\hat{T}_{e} \\
\Delta \varphi_{s}=\varphi_{s}-\hat{\varphi}_{s}
\end{array}\right.
$$

and the inverter switching states are determined by the torque and flux errors according to the determined sector. When the torque is equal or close to its reference value, the three VSI voltage vectors should be arranged in a symmetrical order.

\section{SIMULATIONS RESULTS}

Numerical simulations have been carried out on an EV propelled by a $37-\mathrm{kW}$ induction motor drive which ratings are summarized in the appendix (Fig. 4). In the appendix are also given the electrical vehicle mechanical and aerodynamic characteristics. The objectives of the carried out simulations are to assess the efficiency and dynamic performances of the proposed sensorless DTC strategy. The test cycle is the urban ECE-15 cycle. A driving cycle is a series of data points representing the vehicle speed versus time. This driving cycle represents urban driving. It is characterized by low vehicle speed (maximum $50 \mathrm{~km} / \mathrm{h}$ ) and is useful for testing small EVs performance.

For sensorless purposes, an estimator scheme for the rotor speed, the torque and the flux is proposed on a fourth-order electrical model basis. The sensorless DTC strategy performance are first illustrated by Figs. 5 and 6 that show, respectively, the speed and the developed torque with changes of the acceleration pedal position and a varied road profile. It should be noticed that speed and torque variations are as large as are the variations of the accelerator pedal and the road profile. It is obvious that the proposed strategy operates satisfactorily.

\section{EXPERIMENTAL RESULTS}

\section{A. The Experimental Setup} 7):

The main components of the experimental setup are (Fig.

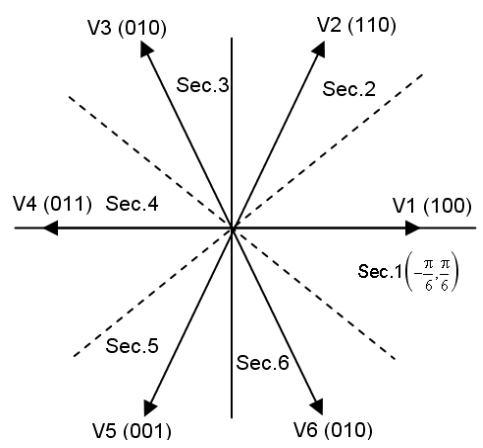

(a) Output voltage vectors.

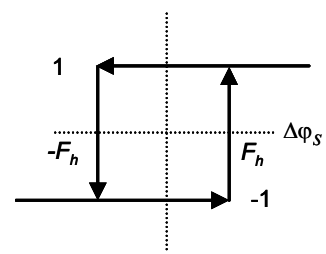

(b) Flux comparator.

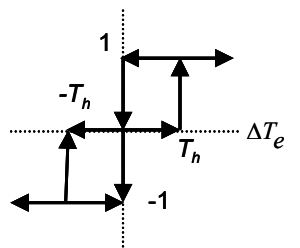

\begin{tabular}{|c|c|c|c|c|c|c|c|}
\hline & & 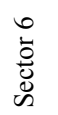 & $\begin{array}{l}n \\
\stackrel{0}{0} \\
\stackrel{d}{\mathscr{S}}\end{array}$ & 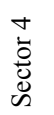 & $\begin{array}{c}m \\
\stackrel{0}{0} \\
\tilde{D} \\
\tilde{n}\end{array}$ & $\begin{array}{c}\text { N } \\
\dot{0} \\
\stackrel{0}{0} \\
\mathscr{D}\end{array}$ & 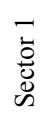 \\
\hline & & 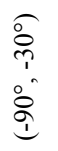 & $\begin{array}{l}\text { } \\
\text { r } \\
\stackrel{8}{0} \\
\stackrel{9}{1}\end{array}$ & $\begin{array}{l}\text { ᄋ̊ } \\
8 \\
\stackrel{0}{0} \\
\stackrel{0}{0}\end{array}$ & $\begin{array}{l}\text { } \\
\stackrel{8}{2} \\
\stackrel{1}{0} \\
\dot{8}\end{array}$ & 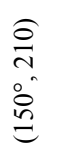 & 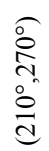 \\
\hline \multirow{2}{*}{$\begin{array}{c}\text { Decrease } \\
\text { Flux }\end{array}$} & $\begin{array}{c}\text { Increase } \\
\text { Torque }\end{array}$ & 100 & 110 & 010 & 011 & 001 & 101 \\
\hline & $\begin{array}{c}\text { Decrease } \\
\text { Torque }\end{array}$ & 011 & 001 & 101 & 100 & 110 & 010 \\
\hline \multirow{2}{*}{$\begin{array}{c}\text { Increase } \\
\text { Flux }\end{array}$} & $\begin{array}{c}\text { Increase } \\
\text { Torque }\end{array}$ & 110 & 010 & 011 & 001 & 101 & 100 \\
\hline & $\begin{array}{c}\text { Decrease } \\
\text { Torque }\end{array}$ & 001 & 101 & 100 & 110 & 010 & 011 \\
\hline
\end{tabular}

(c) Three-level torque comparator. (d) Switching table.

Fig. 3. Switching table and comparators for the induction motor DTC.

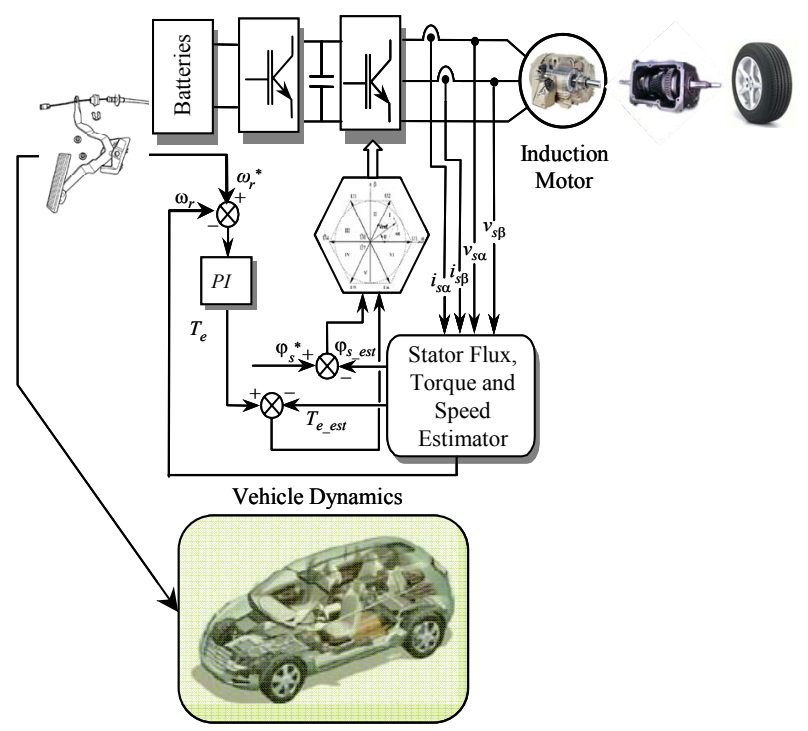

Fig. 4. Scheme for the EV sensorless DTC simulation. 


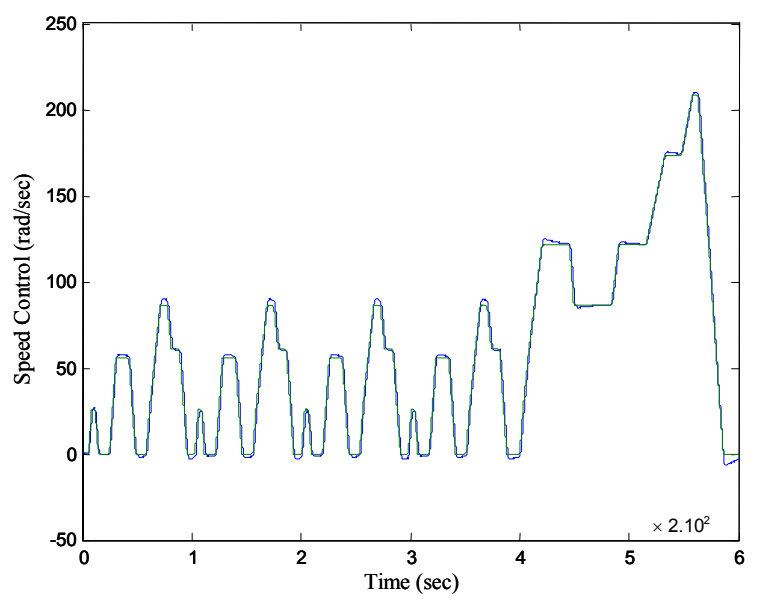

Fig. 5. Estimated and measured vehicle speed.

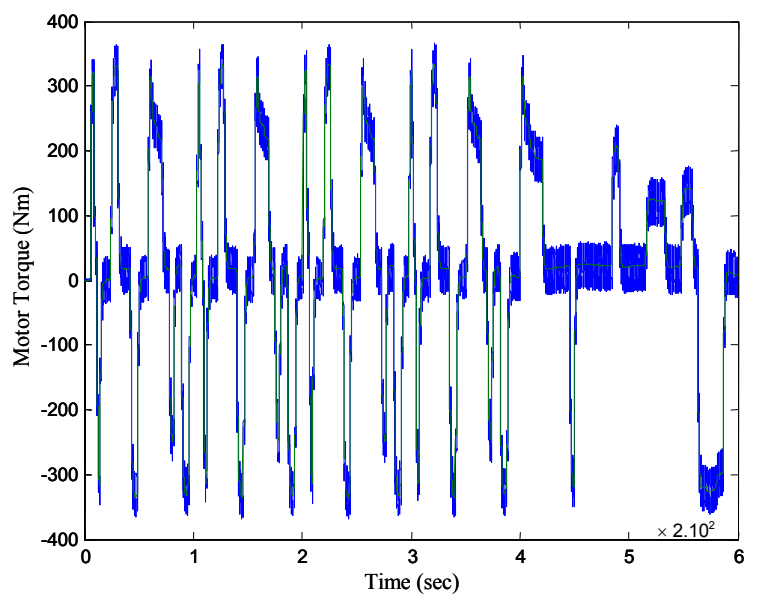

Fig. 6. Developed and estimated motor torque.
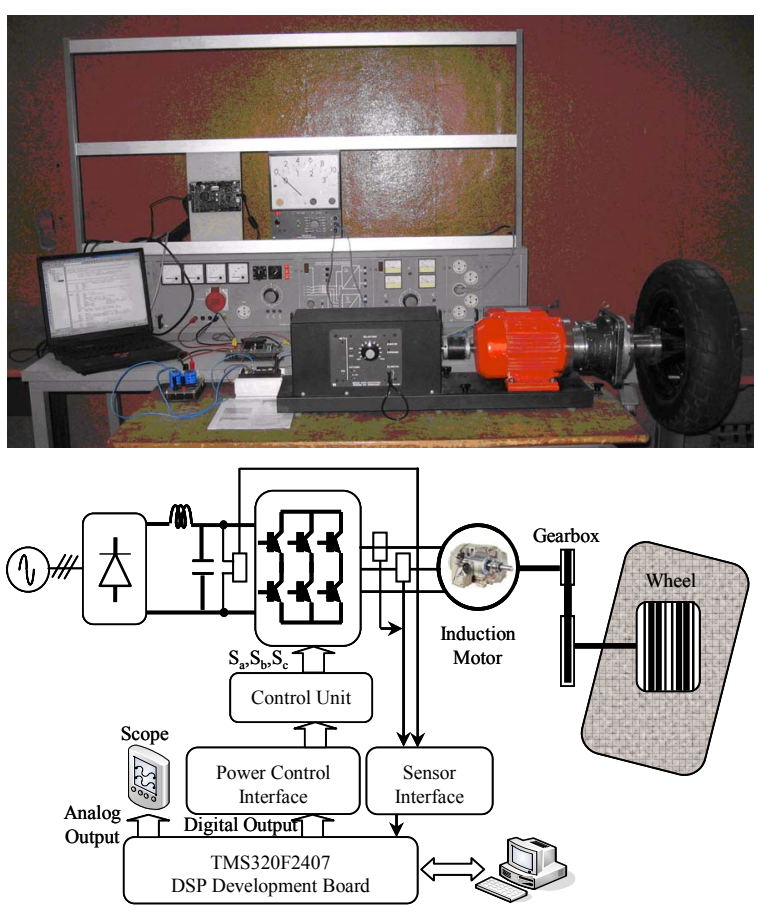

Fig. 7. The experimental setup. a DSP system (single fixed-point TMS320F240 DSP-based development board), an optical encoder attached to the motor shaft only to allow comparison between estimated and measured speed, and current sensors. The DSP system is interfaced to a standard PC. The continuous-time algorithm is discredited with a sampling period of $100 \mu \mathrm{s}$. At each sampling instant, the DSP receives stator currents and voltages measurements and then runs the estimation algorithm and the DTC scheme.

\section{B. The Experiments}

Experimental tests have been carried out to test the estimation algorithm. For that purpose, a 1-kW induction motor drive, which ratings are summarized in the appendix, has been used. In this case the EV dynamics is not taken into account.

The estimation algorithm was tested in various speed regions and various conditions. As shown in Fig. 8, the estimator was seen to work well under various circumstances. Hence the proposed approach (DTC associated to a full order observer estimator) allows the torque, the rotor speed, and the current ripple to be reduced that is of great importance for and EV application.

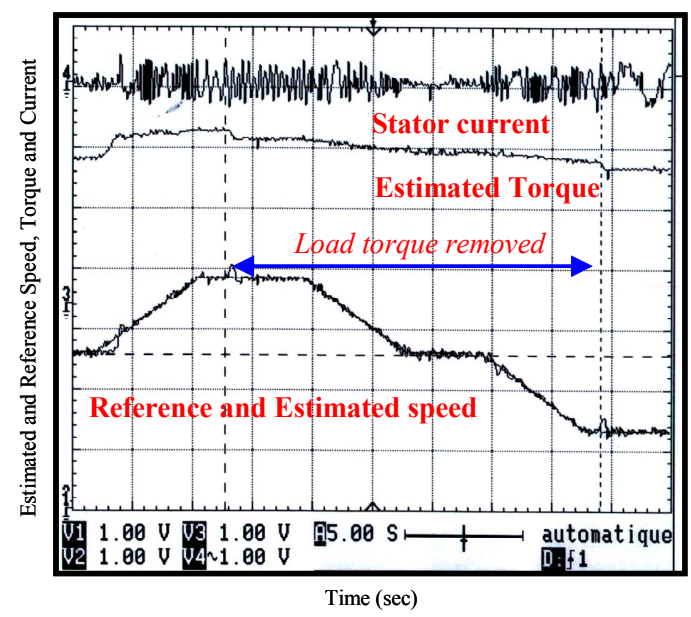

(a) From low to high speed operation.

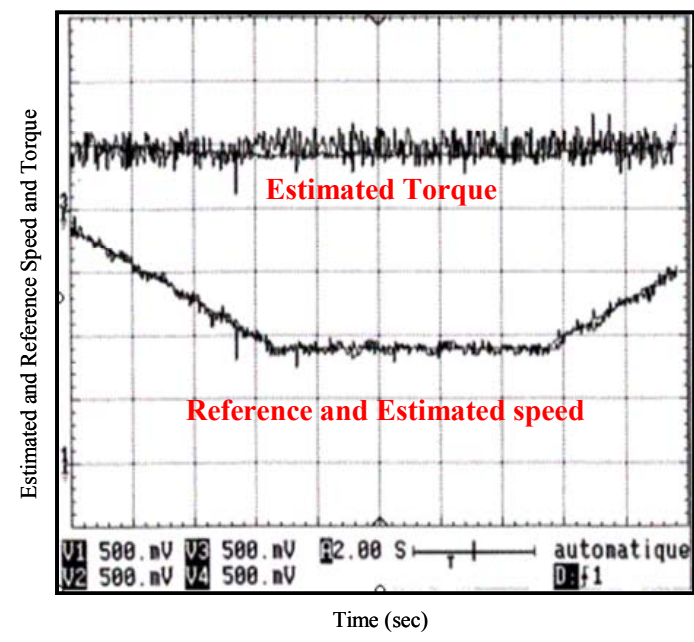

(b) Low speed operation at rated load. 


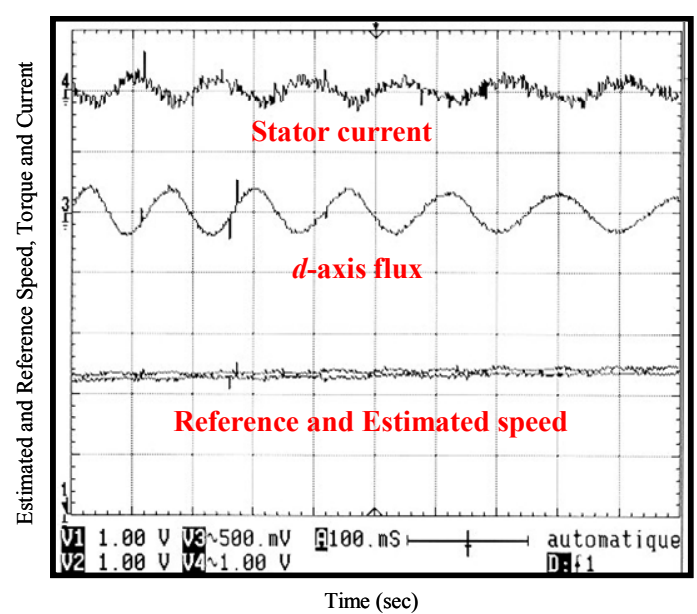

(c) Zoom during low speed operation.

Fig. 8. Experimental results.

\section{CONCLUSION}

In this paper a sensorless control was proposed to increase the efficiency of a DTC of an induction motor propelling an EV. The proposed scheme uses an adaptive flux and speed observer that is based on a full order model of the induction motor. It was successfully simulated on a $37-\mathrm{kW}$ induction motor drive taking into account the vehicle dynamics. In this case, the commonly used European drive cycle ECE-15 was adopted. The estimation was then experimentally tested on a $1-\mathrm{kW}$ induction motor drive. Experimental results show that the sensorless scheme is effective in terms of speed and torque performances. Indeed, it is capable of working from very low to high speed and exhibits very good dynamics. Moreover, the proposed approach (DTC associated to a full order observer estimator) allows the torque, the rotor speed, and the current ripple to be reduced that is of great importance for and EV application.

The obtained results show that the sensorless DTC scheme for induction motors is a good candidate for EVs propulsion.

\section{APPENDIX}

RATED DATA OF THE SiMUlated INDUCTION MOTOR

$37 \mathrm{~kW}, 50 \mathrm{~Hz}, 400 / 230 \mathrm{~V}, 64 / 111 \mathrm{~A}, 24.17 \mathrm{Nm}, 2960 \mathrm{rpm}$ $R_{\mathrm{s}}=85.1 \mathrm{~m} \Omega, R_{r}=65.8 \mathrm{~m} \Omega$

$L_{s}=31.4 \mathrm{mH}, L_{r}=29.1 \mathrm{mH}, L_{m}=29.1 \mathrm{mH}$ $J=0.23 \mathrm{~kg} \cdot \mathrm{m}^{2}$
RATED DATA OF THE TESTED INDUCTION MOTOR

$1 \mathrm{~kW}, 50 \mathrm{~Hz}, 400 / 230 \mathrm{~V}, 3.4 / 5.9 \mathrm{~A}, 7 \mathrm{Nm}, 2890 \mathrm{rpm}$ $R_{s}=4.67 \Omega, R_{r}=8 \Omega, L_{s}=L_{r}=0.347 \mathrm{H}, M=0.366 \mathrm{H}$ $J=0.06 \mathrm{~kg} \cdot \mathrm{m}^{2}, \beta=0.042 \mathrm{Nm} . \mathrm{sec}$

EV Mechanical and AEROdynamic PARAMETERS

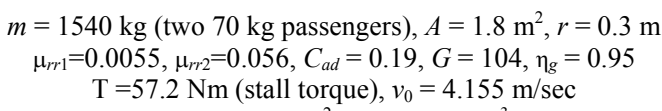

\section{REFERENCES}

[1] C.C. Chan, "The state of the art of electric and hybrid vehicles," Proceedings of the IEEE, vol. 90, n², pp. 247-275, February 2002.

[2] M.E.H. Benbouzid et al., "Electric motor drive selection issues for HEV propulsion systems: A comparative study," IEEE Trans. Vehicular Technology, vol. 55, n6, pp. 1756-1764, November 2006.

[3] D. Diallo et al., "A fault-tolerant control architecture for induction motor drives in automotive applications," IEEE Trans. Vehicular Technology, vol. 53, nº, pp. 1847-1855, November 2004.

[4] S.N. Vukosavic et al., "A method for transient torque response improvement in optimum efficiency induction motor drives," IEEE Trans. Energy Conversion, vol. 18, n4, pp. 484-493, December 2003.

[5] A. Haddoun, M.E.H. Benbouzid and D. Diallo, "A loss-minimization DTC scheme for EV induction motors," IEEE Trans. Vehicular Technology, vol. 56, $\mathrm{n}^{\circ} 1, \mathrm{pp}$. 81-88, January 2007.

[6] D.O. Neacsu et al., "Comparative analysis of torque-controlled IM drives with applications in electric and hybrid vehicles vehicle," IEEE Trans. Power Electronics, vol. 16, n², pp. 240-247, March 2001.

[7] J. Faiz, and $a l$, "Direct torque control of induction motor for electric propulsion systems", Electric Power Systems Research, vol. 51, pp. 95101, 1999.

[8] C. Lascu and al., "A sensorless hybrid DTC drive for high-volume lowcost applications," IEEE Trans. Industrial Electronics, vol. 51, n5, pp 1048-1055, October 2004

[9] J. Faiz et al., "Sensorless direct torque control of induction motors used in electric vehicle," IEEE Trans. Energy Conversion, vol. 18, n 1 , pp. 1 10, March 2003

[10] K. Jezernik, "Speed sensorless torque control of induction motor for EV's", in Proceedings of IEEE IWAMC'02, pp. 236-241, Maribor (Slovenia), 2002

[11] J. Faiz and al., "Different techniques for real time estimation of an Induction motor rotor resistance in sensorless direct torque control for electric vehicle," IEEE Trans. Energy Conversion, vol. 16, nº 1, pp. 104109, March 2001.

[12] I. Husain and al., "Design, modeling and simulation of an electric vehicle system," SAE Technical Paper Series, Paper \# 1999-01-1149.

[13] H. Kubota and al., "Dsp-based speed adaptive flux observer for induction motor," IEEE Trans. Industrial Applications, vol. 29, pp. 344348, March/April 1993. 